\title{
BM] open International medical graduates in the USA: a qualitative study on perceptions of physician migration
}

\author{
P G Chen, ${ }^{1}$ M Nunez-Smith, ${ }^{2}$ D Berg, ${ }^{3}$ A Gozu, ${ }^{4}$ S Rulisa, ${ }^{5}$ L A Curry ${ }^{1,6}$
}

To cite: Chen PG, Nunez-Smith M, Berg D, et al. International medical graduates in the USA: a qualitative study on perceptions of physician migration. BMJ Open 2011;1: e000138. doi:10.1136/ bmjopen-2011-000138

- Prepublication history for this paper is available online. To view these files please visit the journal online (http:// bmjopen.bmj.com).

Received 8 April 2011 Accepted 8 August 2011

This final article is available for use under the terms of the Creative Commons Attribution Non-Commercial 2.0 Licence; see http://bmjopen.bmj.com

${ }^{1}$ Division of Health Policy and Administration, Yale University School of Public Health, New Haven,

Connecticut, USA

${ }^{2}$ Section of General Internal Medicine, Yale University School of Medicine, New Haven, Connecticut, USA ${ }^{3}$ Department of Psychiatry, Yale University School of Medicine, New Haven, Connecticut, USA

${ }^{4}$ Department of Internal

Medicine, Franklin Square

Hospital, Baltimore,

Maryland, USA

${ }^{5}$ Department of Clinical

Research, University

Teaching Hospital of Kigali, Kigali, Rwanda

${ }^{6}$ Yale Global Health Leadership Institute, New Haven, Connecticut, USA

Correspondence to Dr Peggy G Chen; peggy.chen@yale.edu

\begin{abstract}
Objectives: Physician migration from low-income to high-income nations is a global concern. Despite the centrality of understanding the perspectives of international medical graduates (IMGs) who have experienced migration to understanding the causes and consequences of this phenomenon, empirical literature is limited. The authors sought to characterise the experiences of IMGs from limited resource nations currently practicing primary care in the USA, with a focus on their perspectives on physician migration. Design: The authors conducted a qualitative study utilising in-depth, in-person interviews and a standardised interview guide. The sample comprised a diverse, purposeful sample of IMGs $(n=25)$ from limited resource nations (defined as having $\leq 2$ physicians per 1000 population).
\end{abstract}

Results: Analyses revealed four recurrent and unifying themes reflecting the perspectives of IMGs in the USA on physician migration: (1) decisions to migrate were pragmatic decisions made in the context of individual circumstance; (2) the act of migration ultimately affected participants' ability to return home in multiple, unpredictable ways; (3) the ongoing process of acclimation was coupled with inherent conflicts surrounding the decision to remain in the USA; and (4) the effects of policies in both the home country and in the USA occurred at multiple levels.

Conclusion: The perspectives of IMGs who have migrated to the USA are an important addition to the ongoing discussion surrounding the global health workforce. Our findings highlight the effects of workforce policies which are often developed and discussed in abstraction, but have real, measurable impacts on the lives of individuals. Future efforts to address physician migration will need to acknowledge the immediate needs of the health workforce as well as the long-term needs of individuals within health systems.

\section{BACKGROUND}

Physician migration from low-income to high-income nations is a global concern. ${ }^{12}$ In the USA, UK, Canada and Australia, migrant physicians account for $20 \%-30 \%$ of the physician workforce. ${ }^{1}{ }^{3}{ }^{4}$ In the USA, international medical graduates (IMGs),

\section{ARTICLE SUMMARY}

\section{Article focus}

- International medical graduates (IMGs) play a significant role in the health workforce in many nations.

- Prior literature has largely limited the consideration of physician migration to isolated factors such as financial pressures in the home country or expanded training opportunities in the USA.

- The experiences and perspectives of IMGs have not been included in current discussions surrounding physician migration.

\section{Key messages}

- Physician migration is influenced by multifaceted aspects of experience including individual, environmental and political factors.

- IMGs report that both local and global health workforce policies have an impact on their personal and professional lives.

- A comprehensive understanding of physician migration is essential to the development of effective and appropriate solutions for global health workforce challenges.

Strengths and limitations of this study

- Participants were diverse with regard to age, specialty, geographical regions of origin and years of clinical experience in the USA.

- The study utilised recommended strategies to ensure rigour.

- The high participation rate suggests this is an issue IMGs are motivated to discuss despite the potentially personal and sensitive nature of the topic.

- As a qualitative study, the hypotheses generated should be tested with larger, quantitative studies.

- The study was geographically circumscribed to metropolitan regions. Other regions, particularly rural areas, may present a substantially different environment and experience.

defined as physicians who attended medical school outside the USA or Canada, play an important role in primary care ${ }^{5-10}$ care for vulnerable populations ${ }^{11} 12$ and care in physician shortage areas. ${ }^{11} 1314$ Significant literature has been dedicated to elucidating 
the potential costs of physician migration. ${ }^{15-20}$ However, the motivations behind physician migration have been less thoroughly explored.

Extant literature has largely approached the reason for migration as a single decision point. ${ }^{1}{ }^{21-24}$ Among health workers in the African diaspora, Clemens $e t a l^{25}$ report an inverse relationship between economic and political stability and physician migration. Evidence from India indicates that perceived greater professional opportunities drive many potential migrant physicians. ${ }^{26}$ Similarly, a survey in Pakistan indicated that low remuneration and poor training and work environment influenced potential migrant physicians. ${ }^{27}$ Finally, factors such as changing medical school curricula ${ }^{17}$ and the greater likelihood of graduates from higher quality institutions to migrate have also been examined quantitatively. ${ }^{28} 29$

Recent calls to approach physician migration as a symptom of problems in the home country emphasise the need for greater understanding of the complex decisions leading to migration. ${ }^{30}$ However, prior studies have not utilised qualitative methods to capture these complex experiences that contribute to migration. The policy debate surrounding physician migration in the USA is multi-faceted, with recommendations to limit physician migration ${ }^{21}$ 31-42 weighed against the decisions of individual physicians ${ }^{43} 44$ and ongoing gaps in the US physician workforce. ${ }^{45-47}$ The perspectives of IMGs who have migrated and subsequently chosen to remain in the USA are vital to developing a comprehensive understanding of the causes and consequences of physician migration. They may also improve understanding of the effects of workplace and workforce policies and contribute to creative approaches for addressing domestic and global workforce challenges. In this analysis, we sought to characterise the experiences of IMGs from limited resource nations currently practicing in the USA with a focus on their perspectives on the phenomenon of physician migration.

\section{METHODS}

We chose a qualitative design to characterise participant perspectives and generate hypotheses for future testing in larger, quantitative studies. This approach is optimal for capturing the essential aspects of a phenomenon from the perspective of study participants, when addressing potentially sensitive subjects, and when there may be fear of reprisals or repercussions. ${ }^{48} 49$

\section{Study design and sampling}

We conducted one-on-one interviews ${ }^{50}$ with non-US born IMG physicians who completed residency training in the USA and were in outpatient primary care practice (family medicine, internal medicine and paediatrics). Physicians were included if their home country met our definition of a limited resource nation: countries identified by the WHO as having $<2$ physicians per 1000 individuals in the population (the USA has 2.56 physicians per 1000 individuals). ${ }^{51}$ To construct the sample, we utilised the strategy of random purposeful sampling ${ }^{49}{ }^{52}$ in which groups of interest (gender, specialty, region of origin) were identified and key informants within each group were randomly selected to achieve a diverse sample.

We identified potential participants through: the American Medical Association's IMG Section roster; state licensure board databases for Connecticut, New York and New Jersey; and department chairs at regional institutions. Recruitment and data collection were conducted until thematic saturation, ${ }^{49}$ the point at which no new concepts emerge from subsequent interviews, was achieved. The Human Investigation Committee at Yale University School of Medicine approved the research protocol. All participants provided verbal informed consent. In total, 27 physicians were contacted and 25 agreed to participate (93\% participation rate). Two physicians declined to participate due to scheduling conflicts.

\section{Data collection}

One researcher (PC), a paediatrician, a second-generation immigrant and member of an ethnic minority group, conducted all in-person interviews.

The interview guide (box 1) consisted of open-ended, 'grand tour' questions ${ }^{49} 53$ including: "Please share your thoughts on physician migration either on a personal level or from a population level". Probes were used to

\section{Box 1 Interview guide and illustrative probes}

1. Tell me about your experiences working in the USA as an IMG [international medical graduate] physician. Potential probes:

What is good (and/or challenging) about being an IMG physician?

How has being an IMG physician influenced your professional life?

Have you ever felt that your career choices were expanded (or limited) because you are an IMG physician?

2. Could you talk a little about sources of support during training and throughout your career? Potential probes: Were there many other IMG physicians where you trained or where you work now and how does that affect your experience?

Can you talk about your experience with formal and informal support networks?

Were there any particular pieces of curriculum in your training that were helpful/unhelpful?

Could you talk about sources of support that you think should exist for IMG physicians?

3. How are your professional relationships (with patients, other physicians, support staff) affected by your status as an IMG physician? Potential probes:

Have your workplace relationships differed in the various places where you have worked; if so, how?

4. Please share your thoughts on the phenomenon of physician migration either on a personal or a population level. Potential probes:

Current relationship with home country, feelings about migration.

Individual versus collective identity as an IMG physician. 
encourage clarification and elaboration on specific sources of support. Probes are not standardised, and their use is highly contextual for each interview. ${ }^{49}$ Interviews were audio-taped, professionally transcribed and reviewed to ensure accuracy. Interviews lasted an average of $45 \mathrm{~min}$ and participants completed a brief demographic survey at the conclusion of the interview.

\section{Analysis}

Analysis was performed by five-person multidisciplinary teams including a paediatrician, family physician, internists (including an IMG), an organisational psychologist, and health services researchers each with training and expertise in qualitative methods. We developed a code structure in stages and in accordance with the principles of grounded theory, ${ }^{54}$ using systematic, inductive procedures to generate insights grounded in the views expressed by study participants.

First, the full research team independently coded three transcripts, meeting to negotiate consensus over differences in independent coding. We developed codes, or tags to classify data inductively, ${ }^{54}$ drafting an integrated code structure. ${ }^{55}$ We used the constant comparison $\operatorname{method}^{55}$ to ensure that emergent themes were consistently classified, expand on existing codes, identify novel concepts and refine codes. Second, a core team of three analysts (PC, AG and Susannah Bernheim) independently coded all remaining transcripts and reconciled differences through consensus; the full team participated in analysis meetings and finalised a comprehensive code structure capturing all data concepts related to physician migration. PC then systematically applied the final code structure to all transcripts.

At several stages throughout the iterative process of data collection and analysis, we conducted participant confirmation $^{48} 4955$ in which summary results were distributed to participants to confirm that the developing themes accurately reflected participants' experience. We used qualitative analysis software (ATLAS.ti 5.0; Scientific Software Development, Berlin, Germany) to facilitate data organisation and retrieval.

\section{RESULTS}

\section{Demographics}

Our final sample consisted of 25 IMG physicians (table 1). We achieved broad representation with regard to age, specialty, geographical region of origin and years of clinical experience in the USA. The mean number of physicians per 1000 of the population in participants' home countries was 0.74 (range 0.03-1.88; USA 2.56). All respondents were at various stages in the process of seeking permanent residency status or citizenship in the USA.

\section{Themes}

Our focused analysis revealed four recurrent and unifying themes which reflect the perspectives of IMGs in this study regarding physician migration: (1) decisions to migrate were pragmatic decisions made in the context

\begin{tabular}{lc}
\multicolumn{2}{l}{ Table 1 Characteristics of study participants } \\
\hline Characteristic & \multicolumn{1}{l}{ Result $^{*}$} \\
\hline Median age (range), years & $46(30-65)$ \\
Female & $11(44)$ \\
Specialty & \\
Family practice & $7(28)$ \\
Paediatrics & $8(32)$ \\
Internal medicine & $10(40)$ \\
Region of origin & \\
Sub-Saharan Africa & $6(24)$ \\
South Asia & $8(32)$ \\
East Asia & $5(20)$ \\
Latin America & $2(8)$ \\
Middle East & $4(16)$ \\
Years since completed residency & \\
$0-5$ years & $5(20)$ \\
$6-10$ years & $6(24)$ \\
$11-15$ years & $7(28)$ \\
$16-20$ years & $3(12)$ \\
$20-25$ years & $1(4)$ \\
$>25$ years & $3(12)$ \\
\hline Mean number of physicians/1000 in home country (range) 0.74 \\
(0.03-1.88). \\
$*$ Results are mean (range) for age and number (\%) for all other \\
variables.
\end{tabular}

of individual circumstance; (2) the act of migration ultimately affected participants' ability to return home in multiple, unpredictable ways; (3) the ongoing process of acclimation was coupled with inherent conflicts surrounding the decision to remain in the USA; and (4) the effects of policies in both home country and in the USA occurred at multiple levels.

\section{Decisions to migrate were pragmatic decisions made in the} context of individual circumstance

Participants' decisions to leave their home country resulted from the particularities of their situation, such as economic conditions, political environments and opportunities for professional advancement. This family practitioner from East Asia emphasised the realities of life at home:

When you are raised in a third world country, your outlook is on survival. It is not on the nebulous concept of, will I deprive my countrymen if I leave. That is a big difference in thinking... Over here, on a resident's salary... you won't have luxuries, but you won't go hungry... It is a matter of survival... If I could have the same standard of living I have here as I do in [home country] would I prefer to practice in [home country]? Yes.

For this internist from the Middle East, the decision to leave their home country had been the result of an untenable political situation, highlighting the trade-offs inherent in migration:

I came [here] because... there was no hope that they were going to turn the country back into a democratic, civilised country. And so America has nothing to do with it. It's not like a magnet that they welcome us and we 
stayed. It's the condition that we run away from... you're choosing between... worse and worst. Whether you want to go through the culture shock and language shock and all the barriers as... goddamn foreigner, or you want to stay in your country, which you belong to, you were raised in, but have no quality of life... So that is why people run away and come to America.

Similarly, this paediatrician from the Middle East described the decision to migrate as defending a quality of life that had been eroded as a result of civil conflict, emphasising a difference between temporary migration for educational purposes, and the more permanent status of immigration:

We weren't a starving country. It was one of the oil producers, so we had the good things. Usually as physicians, you live very good, so we didn't have much of physician immigration. Most of the physicians who will go to study... they came back... I personally never thought of leaving the country unless for studying, not for immigration. I [would] never thought of immigration if not for the political situation.

This individual also expressed that governments of both low and high income nations have a role to play in enabling physicians to remain in their home countries:

We can lead the doctors back towards their countries... [but] then we have to provide for them there. They want to stay, let's help them stay. Most important is to help them develop some middles, like nurses and technicians... having programs to talk about... improving health systems... even when you bring people [to the US] for training and you make it difficult for them to stay, I think it is okay in a way... but it is not enough... if people want to stay here, they will find a way to stay... you have to look in other ways to keep physicians in their countries by having them be part of a global program to improve that.

Finally, this paediatrician from sub-Saharan Africa described his own migration to pursue professional opportunities not easily available at home:

Personally, the reason why I came is to seek knowledge and I could quickly get it here... unlike in [home country]... you might have to pay somebody... like hanky panky. You can do very good here... play by the rules, pass the exams and graduate...

The act of migration ultimately affected participants' ability to return home in multiple, unpredictable ways

Even participants who initially did not plan to remain in the USA described how migration had changed them both personally and professionally. Moreover, in many instances, their home countries had also changed in their absence. Participants were thus hesitant to return to their home country for logistic, professional and cultural reasons. This internist from sub-Saharan Africa, who initially migrated because of a civil war at home, described the first trip home after the conflict had ended and his realisation that a permanent return was unlikely:
People would see me... and I would hear oh, he's so American... You just... you don't fit in anymore... you can't go back, as they say. It's really true... I [had] wanted the government to fall so I could go back... that happened and yet... it was a big disappointment...

For this internist from South Asia, migration and working as a physician in the USA revealed conditions at home she had not noticed prior to her migration:

Professionally, now since I have been practising... here... when I go back... and see... sometimes maybe the area is not so clean... maybe it is because there is so much demand and there are so many patients and the expenses and everything. They do not have structured medical system... you see all those differences more clearly once you have been here... When I was there, that was all normal and part of it and there was nothing really glaring about it, but now I go back from here and I see it...

This family practitioner from Latin America described professional and practice differences that factored into the decision to remain in the USA rather than return home:

[At home] it is a cash business... you are really just caring or serving the people who can pay you... I've even heard docs [at home] say... don't cure it on the first visit because then... you only get paid once, whereas if you give something that's not going to take care of it... they will come in for a second visit... I don't think I would be able to adapt to that again.

The ongoing process of acclimation was coupled with inherent conflicts surrounding the decision to remain in the USA

Although participants had left their home country for a variety of reasons, all had either completed or were in the process of seeking permanent residency status or citizenship in the USA. While all acknowledged their commitment and desire to remain in the USA, participants also described ongoing guilt resulting from this decision. For this paediatrician from sub-Saharan Africa, the struggles stemmed from his perception of being trapped by multiple responsibilities and expectations:

\footnotetext{
My intention when I first came over was to... do my residency and go home... but then... with all of these immigration problems, no money, you can't go back, you get trapped in the system. There is no going back... even after acquiring this knowledge, I can't help my people... there are plenty physicians [in the USA] who can do the same thing I do... back home there are not many people who can do the same thing I do...
}

Another paediatrician from sub-Saharan Africa believed that his skills were not being effectively used in the USA, but acknowledged that this allowed his family to live and work in the USA:

I'm very much conscious of the fact that I'm working in an area where... there are many, many doctors to take 
care of the people. In [home country], I could work in an area where... I would be saving some lives every day. That has been a bit of an adjustment, although I always have to just consider my family as a whole... I do look back and... I was... doing more for somebody's life 20 years ago than I do on a daily basis here.

This internist from South Asia described a desire, echoed by many participants, to give back to the home country as a form of repayment for education and other investments the country had made in him:

I thought... I should go back... because I owe them my medical school education. So I... spoke a couple of times... went to visit a couple of times. Almost every year or every other year I go if I get a chance... Even if it's for a week I go there and I try to do as much as I can... I owe this to my country.

\section{Effects of policies both in the home country and in the USA occurred at multiple levels}

Although participants ultimately made migration-related decisions based on individual needs and goals, there was a high level of awareness of the downstream effects of local, national and international policies. This paediatrician from sub-Saharan Africa noted that, while many physicians at home sought to come to the USA for increased educational opportunities, licensing restrictions in their home countries meant that many did not return home because of the additional commitment of time and energy this would require:

Strangely, my training... here is not actually good enough to be a paediatrician in [home country]. I'm like a primary care doctor... but to be a paediatrician I would have to go back to the hospital and do some more training... until I passed... a national exam... each year, there might only be about 5 or 6 paediatricians qualifying in the entire country...

This internist from the Middle East recalled an attempt to modernise the medical school in their home country:

So he took the responsibility to come to US and copy the curriculum of the medical school... and build that medical school and the affiliated hospitals... Our books were packed from US. I mean, when we went to buy our Harrison, I could see they were just ripping the boxes just from US, taking out of the cellophane, and sell[ing] it right there. Our stethoscope, everything. Everything came from US.

This individual commented that the modernised hospital essentially served only the elites of the country with training better suited for ultimate practice in Western nations than in many parts of the home country.

Participants also noted that, due to the expense, time commitment and licensing requirements, only certain physicians are able to take part in physician migration. This has potential negative effects on the remaining workforce. This internist from the Middle East remarked:

It comes from bad policies... People are leaving and it becomes a vicious cycle. The more people who are capable leave, the more inept people come into the power which makes the life more miserable for more capable people so the more capable people will leave.

Finally, this paediatrician from sub-Saharan Africa, who maintains extensive ties with his home country, commented that while many physicians at home migrated to higher-income nations, his home country had, in turn, recruited physicians from lower-income nations:

I go back to [home country] every year... We are very much aware of the medical system in [home country]... They lost large numbers of physicians who... went everywhere in the world and [home country] has become a magnet for... physicians from the rest of Africa... So in turn, the vacuum has been filled by the immigration.

\section{DISCUSSION}

We conducted an in-depth, systematic exploration of the experiences of primary care physicians who migrated from limited resource nations to the USA. Our findings indicate decisions surrounding migration were generally based on individual needs and goals, resulting from a confluence of circumstance in the home country. Subsequent decisions to remain in the USA were frequently unplanned and unintentional, stemming from changes that result from migration and acculturation, as well as circumstances making return to the home country unpalatable or impossible. Finally, despite the emphasis on individual motivations in the migration decision, on reflection participants viewed their decisions in more abstract terms, revealing ongoing struggles with their decisions, opinions on necessary elements for improving the situation in their home countries, and consideration of the effect of their migration on the global health workforce.

These findings have generated hypotheses that might be examined in future work. The current study suggests that these hypotheses include: (1) physician migration is influenced by both personal and environmental circumstances; (2) as initially conceived by IMGs, physician migration is largely intended to be temporary; and (3) decisions to remain in the host country permanently are influenced by the specific costs and benefits afforded by remaining in the host country. These broad hypotheses inform future research questions such as: to what extent is physician migration influenced by individual factors, such as personal and professional goals, compared with the political and economic circumstances of their home countries? What factors are associated with temporary versus permanent physician migrants? What are the relative effects of specific factors contributing to the transition from temporary to permanent migration? Such data may assist both home 
and host countries in designing policies to minimise the impact of physician migration.

Importantly, our findings reflect prior work indicating the role of economic and political stability, ${ }^{25}$ professional opportunities, ${ }^{26}$ poor work environment ${ }^{27}$ and sub-optimal workforce dynamics. ${ }^{28}{ }^{29}$ This study expands the framework to include intended and unintended effects of workforce policies and the broader contexts within which migration decisions are made. While economic and political stability may ultimately result in the retention of many potential migrants, such stability is the result of slow change over time and must include steps towards building human capital. A uniform standard for principles of education and training may be part of this solution, acknowledging the global nature of the health workforce and enabling personal advancement while augmenting human capital at home. Partnerships between limited resource nations and destination country institutions, through research networks or clinical collaborations, offer further opportunities for capacity building in limited resource nations. Finally, medical education is typically provided at low or no cost in limited resource nations, representing a loss of investment when physicians migrate. Proposals to recoup this investment, such as educational bonding schemes $^{356}$ and better regulation and mandated compensation from destination countries to limited resource nations, ${ }^{15}$ require systematic examination.

Our findings should be interpreted in light of the potential limitations of the study. First, as a qualitative study, this work is exploratory in nature. Conclusions are not meant to be generalised. We sought to characterise a range of experiences among a diverse group of IMGs to generate hypotheses that may be tested in future, quantitative studies. Second, we focused on IMG physicians in outpatient primary care specialties because of the concentration of IMGs in these fields. Experiences of IMG physicians in other specialties may differ, particularly in more competitive specialties with fewer IMGs. Additionally, our study was geographically circumscribed to New York, New Jersey and Connecticut, largely metropolitan regions of the country. IMGs in other geographical regions, particularly rural areas, may have different perspectives. Finally, this study did not examine the perceptions and decision-making processes of physicians who returned to limited resource countries following training in the USA. Such data may shed additional light on the relevant issues, although their global distribution makes these data difficult to capture.

There are also a number of strengths to our study. First, participants were diverse with regard to age, specialty, geographical origin and years of clinical experience in the USA. Despite this diversity, the commonalities in participants' experiences and perceptions of physician migration were reflected in the recurring and unifying themes reported. Second, we utilised a number of recommended strategies to ensure rigour: consistent use of an interview guide; audio-taping and independent transcription; standardised coding and analysis; use of researchers with diverse racial/ethnic and professional backgrounds; an audit trail to document analytical decisions; and participant confirmation in which participants reviewed a summary of the data and endorsed the content of the themes. ${ }^{48} 49$ 57-59 Third, our high participation rate suggests that this is an issue IMGs are motivated to discuss in a research context, despite the potentially personal and sensitive nature of the topic.

Global health workforce shortages must be addressed in the context of a comprehensive understanding of motivations. The accurate reflections and perspectives of IMGs are an important addition to ongoing discussions over potential solutions to the global health workforce crisis. ${ }^{60}{ }^{61}$ Our findings highlight the effect of workforce policies, which are often developed and discussed in abstraction, but have real and measurable impacts on individual lives. Ongoing discussions must include the role and responsibilities of high-income nations as well as the actions of limited income nations to arrive at effective strategies for the global health workforce as a whole and the individuals within it.

\section{CONCLUSION}

In 1994, the International Conference on Population and Development concluded: "the long-term manageability of international migration hinges on making the option to remain in one's country a viable one for all people". ${ }^{41}$ Migrating physicians make difficult decisions to leave the countries in which they were born, reared and schooled as the result of a confluence of factors leading participants to believe they lack a future in their home countries either professionally or personally. Attempts to address physician migration will need to address not only the immediate needs of the healthcare delivery workforce, but also the long-term needs of individuals and health systems. Although the road to an ultimate solution may be long, our findings indicate that even small steps towards the end goal may have beneficial effects on the workforce by providing individuals with hope for their futures in their own countries. Such small efforts, taken together over time, can build individuals' faith that health systems can evolve to support the practice of high quality medicine with good outcomes for all.

Acknowledgements The authors thank Susannah Bernheim for contributions to data analysis and interpretation, the American Medical Association IMG section for assistance in recruiting, the Educational Foundation for Foreign Medical Graduates for helpful comments, Dr Jishnu Das and Dr Luis Gabriel Cuervo for their contributions in the peer review process, and all physicians who participated in this study.

Correction notice The "To cite: ..." information and running footer in this article have been updated with the correct volume number (volume 1).

Funding This study was funded by the Robert Wood Johnson Clinical Scholars Program, the Robert Wood Johnson Foundation and the Agency for Healthcare Research and Quality (T32 HS 017589-02T32) and the Yale Global Health Leadership Institute. The research team was independent from the funders, who had no role in the collection, analysis and interpretation of data; in the writing of the report; or the decision to submit the article for publication. 
Competing interests None.

Ethics approval Ethics approval was provided by Yale University Human Investigations Committee.

Contributors PC, MNS and LC conceived of and designed the study. PC, MNS, $\mathrm{DB}, \mathrm{AG}, \mathrm{SR}$ and $\mathrm{LC}$ contributed to the analysis and interpretation of data. PC, MNS and LC drafted the article. PC, MNS, DB, AG, SR and LC revised the article critically for important intellectual content. PC, MNS, DB, AG, SR and LC provided final approval of the version to be published. All authors, external and internal, had full access to all of the data in the study and can take responsibility for the integrity of the data and the accuracy of the data analysis.

Provenance and peer review Not commissioned; externally peer reviewed.

Data sharing statement The study protocol, interview guide and code structure are available from the corresponding author at peggy.chen@yale. edu. No additional data are available. The authors were required by the Yale Human Investigations Committee to destroy all data following final analysis in order to protect the identities of the participants.

\section{REFERENCES}

1. Mejía A, Pizurki H, Royston E; World Health Organization. Physician and Nurse Migration: Analysis and Policy Implications: Report of a WHO Study. Geneva: World Health Organization; [Albany, NY: obtainable from WHO Publications Centre USA], 1979.

2. Zurn P, Dal Poz MR, Stilwell B, et al. Imbalance in the health workforce. Hum Resour Health 2004;2:13-24.

3. Martineau T, Decker K, Bundred P. "Brain drain" of health professionals: from rhetoric to responsible action. Health Policy 2004;70:1-10.

4. Mullan F, Politzer RM, Davis $\mathrm{CH}$. Medical migration and the physician workforce. International medical graduates and American medicine. JAMA 1995;273:1521-7.

5. AMA. IMGs in the United States. Chicago, IL: American Medical Association, 2007.

6. Polsky D, Kletke PR, Wozniak GD, et al. Initial practice locations of international medical graduates. Health Serv Res 2002;37:907-28.

7. Rao V, Cabbabe E, Adams K, et al. International Medical Graduates in the U.S. Workforce. Chicago, IL: American Medical Association, 2007.

8. Smart D. Physician Characteristics and Distribution in the US-2006. Chicago, IL: American Medical Association, 2006.

9. NRMP. Advanced Data Tables for 2007 Main Residency Match. Washington, DC: National Residency Match Program, 2007. Table 5.

10. Pugno PA, Schmittling GT, Fetter GT Jr, et al. Results of the 2005 national resident matching program: family medicine. Fam Med 2005;37:555-64.

11. Hing E, Lin S. Role of international medical graduates providing office-based medical care: United States, 2005-2006. NCHS Data Brief 2009;13:1-8.

12. Morris AL, Phillips RL, Fryer GE Jr, et al. International medical graduates in family medicine in the United States of America: an exploration of professional characteristics and attitudes. Hum Resour Health 2006;4:17-24.

13. Cohen JJ. The role and contributions of IMGs: a U.S. perspective. Acad Med 2006;81:S17-21.

14. Mick SS, Lee SY, Wodchis WP. Variations in geographical distribution of foreign and domestically trained physicians in the United States: 'safety nets' or 'surplus exacerbation'? Soc Sci Med 2000;50:185-202.

15. Mills EJ, Schabas WA, Volmink J, et al. Should active recruitment of health workers from sub-Saharan Africa be viewed as a crime? Lancet 2008;371:685-8.

16. Mullan F. The metrics of the physician brain drain. $N$ Engl $J$ Med 2005;353:1810-18.

17. Loefler IJ. Medical migration. Lancet 2000;356:1196.

18. Buchan J, Jobanputra R, Gough P, et al. Internationally recruited nurses in London: a survey of career paths and plans. Hum Resour Health 2006:4:14-23.

19. World Health Organization. Working for Health: An Introduction to the World Health Organization. Geneva: World Health Organization, 2006.

20. Chen L, Evans T, Anand S, et al. Human resources for health: overcoming the crisis. Lancet 2004;364:1984-90.

21. Ahmad OB. Managing medical migration from poor countries. BMJ 2005;331:43-5

22. Klein D, Hofmeister M, Lockyear J, et al. Push, pull, and plant: the personal side of physician immigration to Alberta, Canada. Fam Med 2009;41:197-201.
23. Siringi S. Kenya government promises to increase doctors' salaries to curb brain drain. Lancet 2001;358:307.

24. Kavalier F. Uganda: death is always just around the corner. Lancet 1998;352:141-2.

25. Clemens MA, Pettersson G. New data on African health professionals abroad. Hum Resour Health 2008;6:1-11.

26. Rao NR, Rao UK, Cooper RA. Indian medical students' views on immigration for training and practice. Acad Med 2006;81:185-8.

27. Syed NA, Khimani F, Andrades M, et al. Reasons for migration among medical students from Karachi. Med Educ 2008;42:61-8.

28. Kaushik M, Jaiswal $\mathrm{A}$, Shah $\mathrm{N}$, et al. High-end physician migration from India. Bull World Health Organ 2008;86:40-5.

29. Kaushik M, Roy A, Bang AA, et al. Quality of medical training and emigration of physicians from India. BMC Health Serv Res 2008;8:279.

30. Clemens M. Health Worker Migration: Disease or Symptom? Washington, DC: Global Health, Global Affairs Council, 2010.

31. Bundred PE, Levitt C. Medical migration: who are the real losers? Lancet 2000;356:245-6.

32. Hagopian A, Thompson MJ, Fordyce M, et al. The migration of physicians from sub-Saharan Africa to the United States of America: measures of the African brain drain. Hum Resour Health 2004;2:17-26.

33. Patel V. Recruiting doctors from poor countries: the great brain robbery? BMJ 2003;327:926-8.

34. Narasimhan V, Brown $\mathrm{H}$, Pablos-Mendez A, et al. Responding to the global human resources crisis. Lancet 2004;363:1469-72.

35. Pang T, Lansang MA, Haines A. Brain drain and health professionals. BMJ 2002;324:499-500.

36. de Mesquita JB, Gorden M. The International Migration of Health Workers: A Human Rights Analysis. London, UK: Medact, 2005.

37. Physicians for Human Rights. An Action Plan to Prevent Brain Drain: Building Equitable Health Systems in Africa. Boston, MA: Physicians for Human Rights, 2004.

38. World Health Organization. International Recruitment of Health Personnel: Draft Global Code of Practice. Paper Presented at: 126th Session. Geneva: World Health Organization, 2009.

39. World Health Organization. WHO Global Code of Practice on International Recruitment of Health Personnel. Paper presented at: Sixty-Third World Health Assembly. Geneva: World Health Organization, 2010.

40. Stilwell B, Diallo K, Zurn P, et al. Migration of health-care workers from developing countries: strategic approaches to its management. Bull World Health Organ 2004;82:595-600.

41. International Conference on Population and Development Cairo, Egypt, 5-13 September 1994 [microform:]. [Cairo]: United Nations, 1994.

42. Second World Rural Health Congress Conference Committee. Second World Rural Health Congress. Durban, South Africa: Rural Doctors Association of Southern Africa, 1997.

43. Srivastava R. A bridge to nowhere-the troubled trek of foreign medical graduates. N Engl J Med 2008;358:216-19.

44. Amore LG. My part in the "brain drain". BMJ 2000;321:841.

45. Association of American Medical Colleges. Physician Shortages to Worsen Without Increases in Residency Training. Chicago, IL: AAMC, 2010.

46. Biviano M, Makarehchi F. National Center for Health Workforce Analysis: Globalization and the Physician Workforce in the United States. Sixth International Medical Workforce Conference. Ottowa Canada: US Department of Health and Human Services: Health Resources and Services Administration, 2002.

47. Baer LD, Konrad TR, Slifkin RT. If Fewer International Medical Graduates are Allowed in the US, Who Might Replace Them in Rural, Underserved Areas? Chapel Hill, NC: NC Rural Health Research and Policy Analysis Program Cecil G. Sheps Center for Health Services Research UNC-Chapel Hill, 2001.

48. Malterud K. The art and science of clinical knowledge: evidence beyond measures and numbers. Lancet 2001;358:397-400.

49. Patton MQ. Qualitative Research \& Evaluation Methods. 3rd edn. Thousand Oaks, CA: Sage Publications, 2002.

50. Britten N. Qualitative interviews in medical research. $B M J$ 1995;311:251-3.

51. World Health Organization. Physician Density Per 1,000 Population Geneva, Switzerland: World Health Organization, 2007.

52. Qualitative Research Guidelines Project. Purposeful Random Sampling. Princeton, NJ: Robert Wood Johnson Foundation, 2008.

53. Miles MB, Huberman AM. Qualitative Data Analysis: An Expanded Sourcebook. 2nd edn. Thousand Oaks: Sage Publications, 1994.

54. Glaser BG, Strauss AL. The Discovery of Grounded Theory; Strategies for Qualitative Research. Chicago: Aldine Publishing Co., 1967. 
55. Bradley EH, Curry LA, Devers KJ. Qualitative data analysis for health services research: developing taxonomy, themes, and theory. Health Serv Res 2007;42:1758-72.

56. Bezuidenhout M, Joubert G, Hiemstra LA, et al. Reasons for doctor migration from South Africa. SA Fam Pract 2009;51:211-15.

57. Mays N, Pope C. Rigour and qualitative research. BMJ 1995;311:109-12.

58. Pope C, Ziebland S, Mays N. Qualitative research in health care. Analysing qualitative data. BMJ 2000;320:114-16.
59. Curry LA, Nembhard IM, Bradley EH. Qualitative and mixed methods provide unique contributions to outcomes research. Circulation 2009;119:1442-52.

60. Department of Health and Ageing. Health Workforce: Rural Medical Bonded Scholarships. http://www.health.gov.au/ mrbscholarships.

61. Habte D, Dussault G, Dovlo D. Challenges confronting the health workforce in sub-Saharan Africa. World Hosp Health Serv 2004;40:23-6. 